\title{
BDNF Promotes the Survival of Rat Sensory Epithelial Cells Via the PI3K/Akt and NF-kB/Bcl-2 Signaling Pathways
}

\author{
Jianmin Huang ${ }^{1, \#}$, Xiaohua $\mathrm{Hu}^{1,2,4, \#}$, Ling Feng ${ }^{2}$, Shinji Fukudome ${ }^{2}$, Yiqing Zheng ${ }^{3}$ and \\ Jizhen $\operatorname{Lin}^{2,4, *}$
}

\author{
${ }^{I}$ Department of Otolaryngology, Fujian Medical University, Fuzhou, China; ${ }^{2}$ Departments of Otolaryngology Head and \\ Neck Surgery, University of Minnesota School of Medicine, Minneapolis, USA; ${ }^{3}$ Departments of Otolaryngology Head \\ and Neck Surgery, Sun Yat-sen University, Guangzhou, China; ${ }^{4}$ The Institute of Immunotherapy, Fujian Medical \\ University, Fuzhou, China
}

\begin{abstract}
Sensory epithelial cells in the organ of Corti survive throughout life. However, factors for sensory epithelial cell survival are poorly understood at the present time. Here we demonstrated that brain-derived neurotrophic factor (BDNF), a factor committing to neuronal survival, promotes the survival of sensory epithelial cells (OC1) through phosphatidylinositide 3'-OH kinase (PI3K)/protein kinase B (Akt) and/or nuclear factor kappa B (NF-кB)/B cell lymphoma 2 (Bcl-2) pathways. BDNF activated PI3K/Akt kinases and increased NF- $\mathrm{BB} / \mathrm{Bcl}-2$ activity or expression in association with the survival of OC1 cells in vitro. LY294002, a specific inhibitor for PI3K, and pyrrolidine dithiocarbamate (PDTC), an inhibitor for NF- $\mathrm{KB}$, abrogated the protective effect of BDNF on $\mathrm{OC} 1$ cells, causing the increased expression of caspase 3 and the apoptotic cell numbers in vitro. Similarly, a dominant negative mutant of I kappa B alpha (IкB $\alpha \mathrm{M}$, a specific inhibitor of NF- $\mathrm{BB}$ ) abrogated the protective effect of BDNF on OC1 cells. The data demonstrate that BDNF promotes the survival of sensory epithelial cells through the PI3K/Akt and NF-кB/Bcl-2 signaling pathways.
\end{abstract}

Keywords: BDNF, cell survival, sensory epithelial cells, cochlea, rat.

\section{INTRODUCTION}

Sensory epithelial cells (hair cells) in the organ of Corti survive throughout life as neurons do in the central nervous system. Factors that contribute to the survival of sensory epithelial cells are poorly understood at the present time but are of considerable significance. The neurotrophins are thought as candidates for survival of sensory epithelial cells due to their roles in the central and peripheral neurons $[1,2]$.

Firstly, the expression of brain-derived neurotrophic factor (BDNF) was detected in the rat organ of Corti [3]. Secondly, BDNF is known as one of the downstream molecules of Brn3.1 [4-6] that is crucial for differentiation and survival of auditory sensory epithelial cells [7]. In humans, mutation of Brn3.1 results in progressive hearing loss starting at the age of $18 \sim 35$ due to the degeneration of sensory epithelial cells [8]. Apparently, abnormality of the Brn3.1-BDNF signaling does not affect the generation of sensory epithelial cells but does affect the survival of developed sensory epithelial cells in the organ of Corti. Developed sensory

\footnotetext{
*Address correspondence to this author at the $20016^{\text {th }}$ Street SE, Room 216 Lions Research Bldg, Minneapolis MN 55455, USA;

Tel: (612) 626-9885; Fax: (612)626-9871; Email: linxx004@umn.edu

\#Jianmin Huang and Xiaohua Hu are equally contributed to this work.

"This study was performed in accordance with the PHS Policy on Human Care and Use of Laboratory Animals, the NIH guide for the Care and Use of Laboratory Animals, and the Animal Welfare Act (7 U.S.C. et seq.); the animal use protocol was approved by the Institutional Animal Care and Use Committee (IACUC) of University of Minnesota."
}

epithelial cells fail to maintain a life-long span when Brn3.1 is mutated. This can be best explained as a lack of BDNF production. The link of BDNF to Brn3.1 transcription factor prompted us to examine the effect of BDNF on sensory epithelial cells and its signaling pathway that leads to survival of sensory epithelial cells in vitro.

Phosphatidylinositide 3'-OK kinase (PI3K) is recently reported to resist gentamycin ototoxicity in postnatal rat organ of Corti [9], suggestive of involvement in the hair cell survival in vivo. BDNF receptor is a tyrosine kinase (TrkB) that activates the PI3K which in turn recruits protein kinase $\mathrm{B}$ (Akt) to the plasma membrane [10,11]. Akt is linked to nuclear factor kappa B (NF- $\mathrm{BB})$ in a cross-talk manner in many types of epithelial cells [12]. We recently found that blockage of PI3K led to cellular apoptosis of cultured cochlear sensory epithelial cells in our pilot study. It is therefore believed that the PI3K/Akt signaling, concurring with $\mathrm{NF}-\kappa \mathrm{B}$, regulates the survival of sensory epithelial cells.

$\mathrm{NF}-\kappa \mathrm{B}$ is a central molecule that is extensively involved in cell growth, proliferation, and survival. Recently, it has been shown that activation of NF- $\mathrm{KB}$ in the cochlear tissue protects sensory epithelial cells from death induced by aminoglycosides [13]. B cell lymphoma 2 (Bcl-2) is a downstream molecule of NF- $\mathrm{KB}$ [14] which may mediate the effects of PI3K/Akt/NF-KB on cellular survival. We found recently that inhibition of NF- $\mathrm{BB}$ with an inhibitor (pyrrolidine dithiocarbamate, PDTC) inhibited DNA synthesis and proliferation of the organ of Corti epithelial cells called OC1 [15] and induced cell death in this study. Accumulating

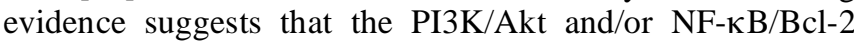


signaling pathways play a role in sensory epithelial cell survival.

Protection of sensory epithelial cells from damage in the cochlear tissue and maintenance of their viability are of considerable clinical importance. We hypothesized in this study that BDNF promotes the survival of sensory epithelial cells via PI3K/Akt and NF- $\mathrm{B} / \mathrm{Bcl}-2$ dependent mechanisms. Our data indicate that $\mathrm{BDNF}$ increased the survival of $\mathrm{OC} 1$ cells through activation of the PI3K/Akt and/or NF- $\mathrm{KB} / \mathrm{Bcl}-2$ pathways. Inhibitors specific for PI3K (LY294002) or for NF- $\kappa$ B (PDTC) abrogated the action by BDNF and caused death of $\mathrm{OC} 1$ cells.

\section{MATERIALS AND METHODS}

Cells and cell culture media. OC1 is an immortalized cochlear sensorineural epithelial cell line from a postnatal Day 5 rat [16]. It was considered to be a progenitor hair cell line because it expressed (i) multiple hair cell markers Brn3.1 (POU4f3), myosin VIIa, $\alpha 9$ Ach receptor, oncomodulin, calretinin, inhibitor of differentiation (Id1 and Id3) $[15,17,18]$ and (ii) early neural cell marker nestin [19] which is positive for most cells in the neuroepithelium before neurogenesis [20]. None of these hair cell markers is specific to cochlear sensory epithelial cells but their expression in combination is restricted to cochlear sensory epithelial cells.

Cells were maintained in Minimal Essential Medium (MEM, Sigma) supplemented with $20 \mathrm{mM}$ HEPES, $2 \mathrm{mM}$ Lglutamine, $10 \mathrm{~mL} / \mathrm{L}$ non-essential animo acid, $0.4 \mu \mathrm{g} / \mathrm{mL}$ hydrocortisone, $5 \mu \mathrm{g} / \mathrm{mLinsulin,} 2.5 \mu \mathrm{g} / \mathrm{mL}$ transferring, 10 $\mathrm{ng} / \mathrm{mL}$ EGF, and $10 \%$ fetal bovine serum (FBS), herein termed full growth media (FGM). During transient transfection of cells, Opti-MEM supplemented with $6 \mu \mathrm{g} / \mathrm{mL}$ of Polybrene ${ }^{\circledR}$ was used (Invitrogen, herein referred to as transfection media).

PDTC, a well-known inhibitor of NF- $\kappa \mathrm{B}$, was purchased from Calbiochem, La Jolla, CA and used as an inhibitor of the NF- $\kappa \mathrm{B}$ activity in this study. PDTC was chosen because it had been worked well on OC1 cells for inhibition of NF$\kappa \mathrm{B}[15]$ and it has been widely used as an inhibitor of $\mathrm{NF}-\kappa \mathrm{B}$, especially in neurons [21] and OC1 cells [15] although it is also an antioxidant inhibitor. A dominant negative mutant of IкB $\alpha$ (IкB $\alpha \mathrm{M}$, a kind gift of Dr. Inder Verma at Salk Institute, La Jolla, CA), in which the serine at position 36 had been changed to alanine, thus preventing phosphorylation and subsequent proteosomal degradation in response to stimuli [22,23].

Specific signaling pathway inhibitors (LY294002, chemically named 2-morpholino-8-phenyl-4H-chromen-4one, SB225002, chemically named N-(2-bromophenyl)-N'(2-hydroxy-4-nitrophenyl)-urea, and PD98059 chemically named 2-(2-Amino-3-methoxyphenyl)-4H-1-benzopyran-4one) were purchased from Calbiochem and used for inhibition of the PI3K, p38, and Erk (mitogen-activated protein kinase) pathways, which are important for cell proliferation and differentiation in the central and peripheral nervous systems [24,25]. Inhibitor concentrations used in this study (PD98059, SB225002, LY294002, each at $20 \mu \mathrm{M}$ ) were from our previous study [26].

Immunohistochemistry. Tissue sections were deparaffinized and rehydrated routinely. OC1 cells were placed in 8- well chamber slides $(50,000$ cells/chamber $)$, incubated with BDNF for 4 days, fixed with $100 \%$ ethanol for 6 minutes at room temperature. Both tissue sections or chamber slide cell cultures were pre-incubated with $3 \%$ normal donkey serum for 15 minutes, incubated with primary and secondary antibodies sequentially with single- or double-staining procedures. Briefly, primary antibodies were phospho-Akt (p-Akt, 1:66 dilution, R\&D); p65 (an NF- $\mathrm{BB}$ subunit, 1:1000 dilution, Abcam); NF-кB (MAB3026, 1:50 dilution, Chemicon, recognizing the active form of $\mathrm{NF}-\kappa \mathrm{B})$; $\mathrm{Bcl}-2(1: 100$ dilution, biomeda); non-specific control antibody $\operatorname{IgG}$ (1:100 dilution, Zymed) and secondary antibodies were fluorescein isothiocyanate (FITC) or tetramethylrhodamine isothiocyanate (TRITC)-conjugated IgG (Zymed). After incubation with antibodies, cells were washed with $0.2 \%$ detergent (TWEEN) in phosphate-buffered saline (PBS), incubated with 4',6-diamidino-2-phenylindole, dihydrochloride (DAPI, $0.7 \mu \mathrm{g} / \mathrm{mL}$ ) for 5 minutes, washed in $0.2 \%$ TWEEN in PBS for 5 minutes, and observed under a microscope (fluorescent or confocal). Positive cells from 6 randomly taken high power fields (HPF, 200x) were counted by two blinded observers and presented as cells/HPF (mean \pm SD, $n=6)$. Positive cells against DAPI-stained nuclei (representing total cells) were calculated in cell cultures.

$H$-thymidine incorporation. Cells were incubated with and without BDNF $10 \mathrm{ng} / \mathrm{mL}$ and $1 \mu \mathrm{Ci}$ of ${ }^{3} \mathrm{H}$-thymidine in MEM containing 4\% FBS for 6, 12, 24, and 72 hours, respectively, washed in PBS twice, and digested in a $0.25 \mathrm{~N}$ of sodium hydroxide and $0.25 \%$ of SDS solution at $37^{\circ} \mathrm{C}$ for one hour, then transferred to $1 \mathrm{~mL}$ of scintillation fluid (Ecoscent A, National Diagnostics), mixed thoroughly, and digested for 2 hours prior to counting (count per minute, CPM) in a scintillation counter (Beckman). Cells from the above experiments were counted with Trypan blue exclusion as previously described [27]. Results are presented as CPM per 10,000 cells, with $n=3$.

Trypan blue exclusion. Briefly, cells were cultured until $50 \%$ confluence, starved in MEM (no supplements) for 24 hours, and treated with and without BDNF at $10 \mathrm{ng} / \mathrm{mL}$ for $6,12,24,48$, or 72 hours, washed in PBS, and incubated in $0.3 \mathrm{~mL}$ of $0.05 \%$ Trypsin-EDTA solution for 10 minutes. Cells treated with BDNF but with and without vehicle (dimethyl sulfoxide, DMSO) served as controls. Five microliters of the trypsin solution was mixed with $5 \mu \mathrm{L}$ of Trypan blue and transferred to the hemacytometer for counting. Results are presented as $10^{6}$ cells. Similarly, cells incubated with and without BDNF in the presence of inhibitors (LY294002, SB225002, or PD98059), washed in PBS, and harvested for cell counts after staining with Trypan blue.

Evaluation of cellular apoptosis. Yopro-1 [4-[3-methyl2,3-dihydro-(benzo-1,3-oxazole)-2-methylmethyledene]-1(3'-trimethyl ammoniumpropyl)-quinilinium diioide, Molecular Probes], which selectively passes through the plasma membranes of apoptotic cells and labels them green, and propidium iodide (Molecular Probe), which stained necrotic cells red [28], was used. OC1 cells at $40 \%$ confluence were incubated with and without BDNF (10 ng/mL) for $10 \mathrm{~min}$ utes before addition of $17 \mu \mathrm{mol} / \mathrm{L}$ camptothecin (Sigma, St. Louis, MO) for 30 minutes. After that, cells were stained with $0.1 \mu \mathrm{mol} / \mathrm{L}$ apoptotic stain Yopro- 1 for 20 minutes and visualized by a fluorescent microscope (E4, Nikon). Photo- 
graphs were taken from 6 randomly selected HPFs from each sample. Images were analyzed using the Scion Image software. The experiment was performed in triplicate.

Fluorescence-activated cell sorting (FACS). Cells at $60 \%$ confluence were starved in MEM for 24 hours, treated with and without BDNF at $10 \mathrm{ng} / \mathrm{mL}$ for 24 hours in MEM, washed in PBS, harvested by trypsinization, and preincubated with $0.3 \%$ saponin in PBS for 10 minutes, incubated with primary and secondary antibodies sequentially: Bcl-2 (1:100 dilution) on ice for 20 minutes, washed with $0.3 \%$ saponin in PBS, incubated with FITC-conjugated secondary antibody on ice for 20 minutes, resuspended in PBS and analyzed on FACSCalibur using CellQuest Pro (BD Sciences). Similarly, FACS for p-Akt (1:66 dilution) and p-p65 (1:50 dilution, Chemicon); caspase 3 (1:100 dilution, Santa cruz); and BrdU (5-bromodeoxyduridine, 1:50 dilution, abcam) were performed. Results are presented as $\%$ of positive cells per 10,000 cells. Non-specific IgG was used as an antibody control. Cells without any stain served as blank controls. For apoptosis analysis, $300 \mu \mathrm{L}$ of $1.33 \mathrm{x}$ Annexin buffer was added to cells, followed by addition of $2 \mu \mathrm{L}$ Annexin-VAPC (BD Biosciences) to cells for 10 minutes at room temperature and finally by addition of 7-amino-actinomycin $\mathrm{D}$ (7-AAD, Invitrogen) to a final concentration of $50 \mathrm{ng} / \mathrm{mL}$ for additional 5 minutes prior to analysis. Annexin V staining identifies early apoptotic cells and 7-AAD staining indicates late apoptotic/necrotic cells.

Cell cycle analysis. For cell cycle analysis, approximately $3-5 \times 10^{5}$ cells were suspended in $100 \mu \mathrm{L}$ of $40 \mu \mathrm{g} / \mathrm{mL}$ DNase-free RNase A with $100 \mu \mathrm{L}$ of $200 \mu \mathrm{g} / \mathrm{mL}$ propidium iodide (DNA dye) added, incubated for 30 minutes at room temperature, and analyzed on an FACScalibur (Becton Dickinson, NJ). Singlets with DNA amount at $2 \mathrm{x}$ were defined as Go/G1 phase cells, $>2 \mathrm{x}$ and $<4 \mathrm{x}$ as S-phase cells, $4 \mathrm{x}$ as G2/M phase cells, and $<2 \mathrm{x}$ as subG1 cells (e.g., apoptotic cells). Approximately 20,000 cells were measured per specimen and the experiment was performed in triplicate. Data was analyzed with FlowJo 7.0 (Tree Star Inc) and typical results are presented.

Affymetrix microarrays. For verification of the BDNF and its signaling pathway relevance in the cochlear tissue, the otocysts and otocapsules of embryonic and postnatal days (E12, E14, E16, E18, and P1) were routinely dissected. RNA was isolated using the StrataPrep ${ }^{\mathrm{R}}$ Total RNA Miniprep Kit (Stratagene). Affymetrix microarrays were performed as previously described [27]. Briefly, cDNA was prepared from $20 \mu \mathrm{g}$ of total RNA using the double-strand DNA synthesis kit (Life Technologies, Rockville, MD). cRNA was synthesized from cDNA and biotinylated using the BioArray High Yield RNA Transcript Labeling Kit (Enzo Diagnostics, Farmingdale, NY). Fifteen $\mu \mathrm{g}$ of fragmented cRNA was hybridized to the Rat U34 set of genechips. Signals were detected with anti-streptavidin antibody and scanned into a computer. Data sets (in triplicates, three batches of RNA samples) from each time point were scaled and relative mRNA expression levels were expressed as relative light unit (RLU, mean $\pm \mathrm{SD}$ ). Data presented in this study were BDNF and related downstream molecules involved in cellular survival.
Statistical analysis. The Student's $t$-test for unequal variances was used for evaluation of two-group studies whereas analysis of variance (ANOVA) was used for evaluation of multiple-group studies. $P$ values less than 0.05 were considered significant.

\section{RESULTS}

$B D N F$ significantly increases the viability and survival of sensory epithelial cells in vitro. To study whether BDNF increases the cellular viability of OC1 cells, Trypan Blue exclusion and Yopro-1 stain were performed. The results indicated that BDNF significantly increased the viable cell numbers (estimated by FACS) and reduced apoptosis (estimated by Yopro-1 stain) compared with controls (Fig. 1A). To confirm the above findings, flow cytometry was performed for evaluation of apoptotic cells: a sub-G1 population that reflects abnormal DNA amount (< normal 2x DNA amount) when compared with control cells. As expected, the sub-G1 population reduced in BDNF-treated cells compared with control cells (Fig. 1B). BDNF-treated cells maintained at a stable level for ${ }^{3} \mathrm{H}$-thymidine incorporation from 6 to 72 hours but untreated cells did not maintain at a stable level for ${ }^{3} \mathrm{H}$-thymidine incorporation so that there was a significant difference between BDNF-treated and untreated cells at 72 hours (Fig. 1C). Consistent with this, cell counts demonstrated that cells treated with BDNF effectively maintained the cell numbers at a higher level whereas untreated cells did not maintain cell numbers at the same level. A significant difference between BDNF-treated and untreated cells at the time point of 72 hours was observed (Fig. 1D). To verify that the cell number increase is not due to cell proliferation but cellular survival, we incubated OC1 cells with BDNF for 12 hours from $10 \mathrm{ng} / \mathrm{mL}$ to $50 \mathrm{ng} / \mathrm{mL}$ and evaluated DNA synthesis and cell numbers by ${ }^{3} \mathrm{H}$-thymidine incorporation and cell counts (Trypan blue exclusion). It was found that BDNF did not show a significant increase on the DNA synthesis (Fig. 1E) and cell counts (Fig. 1F) in a dose-dependent manner.

BDNF significantly protects OC1 cells from camptothecin-induced cell death. To study whether BDNF truly protects sensory epithelial cells from death, cell protection assays were performed on OC1 cells using Yopro-1 as a probe for identification of apoptotic cells and propidium iodide as another probe for identification of necrotic cells. Camptothecin is used in this study because it is a universal inducer of cellular apopotosis (more potent than aminoglycosides in a short period of time to OC1 cells in our pilot studies). Incubation of OC1 cells with camptothecin for 30 minutes induced cell death in a concentration-dependent manner ranging from 0.01 to $0.04 \mu \mathrm{g} / \mathrm{mL}$ (Fig. 2A-D). Camptothecin at $0.04 \mu \mathrm{g} / \mathrm{mL}$ induced the necrosis and/or apoptosis almost in the all cells (Fig. 2E-H). Camptothecin at the concentration of $0.04 \mu \mathrm{g} / \mathrm{mL}$ was, therefore, used for induction of apoptosis and necrosis in this experiment. Incubation of OC1 cells with camptothecin at $0.04 \mu \mathrm{g} / \mathrm{mL}$ induced the cell death in a necrotic (Fig. 2F) or apoptotic (Fig. 2G) manner whereas incubation of OC1 cells with BDNF at $20 \mathrm{ng} / \mathrm{mL}$ remarkably protected cells from necrosis (Fig. 2J) and/or apoptosis (Fig. 2K). To calculate cell numbers that underwent apoptosis or necrosis from slides, total cell numbers were counted by nuclear dye (DAPI) stain, dead cells were counted from 6 HPFs and averaged out. The above experiment was performed in 
A

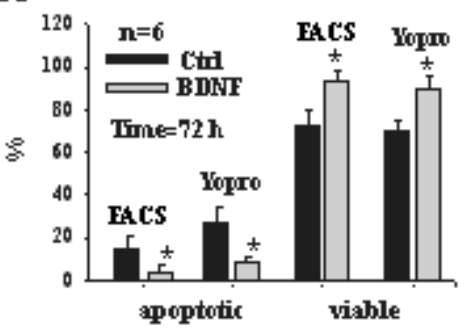

$\mathrm{C}$

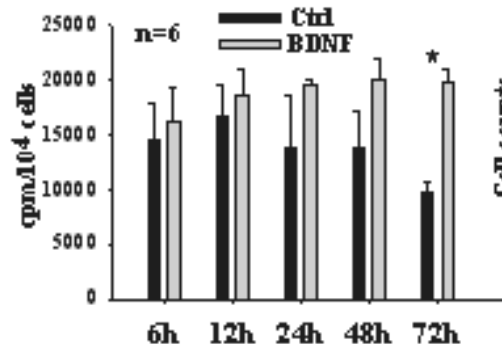

6h 12h 24h 48h 7 ?h

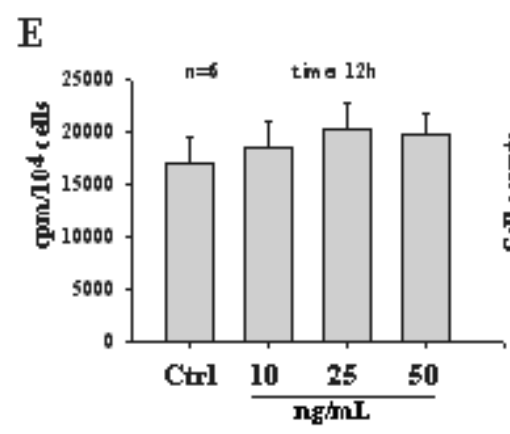

B

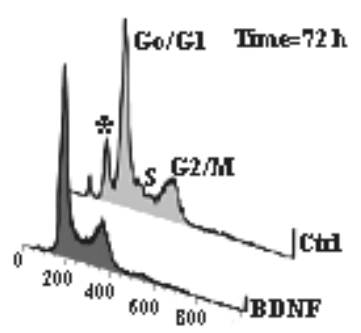

$\mathrm{D}$

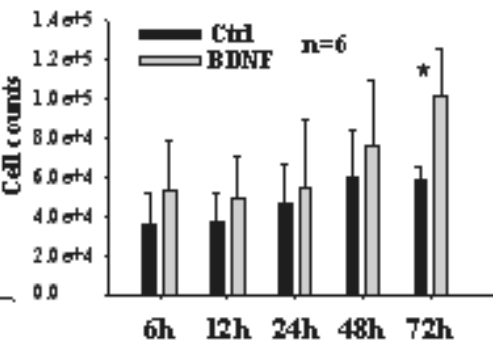

$\mathbf{F}$

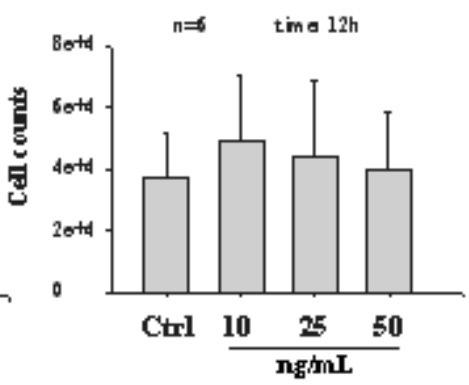

Fig. (1). BDNF increases the viable cell numbers of cultured OC1 cells through an increased survival mechanism. Apoptosis analysis by FACS and Yopro-1 indicated that BDNF significantly reduced apoptotic cell numbers and increased viable cell numbers (A). Flow cytometry on cellular DNA demonstrated that cells without BDNF showed a sub-G1 population (DNA amount in the nucleus less than 2x) whereas cells treated with BDNF showed no or few sub-G1 cells $(\mathbf{B})$. The ${ }^{3} \mathrm{H}$-thymidine incorporation maintained from 6 to 72 hours in cells with BDNF whereas the ${ }^{3} \mathrm{H}$-thymidine incorporation significantly reduced at 72 hour in cells treated without BDNF (C). Correspondingly, Trypan Blue demonstrated that viable cells in BDNF-treated group were significantly higher those in control group (D). Incubation of OC1 cells with BDNF from 10 to $50 \mathrm{ng} / \mathrm{mL}$ for 12 hours did not significantly change the ${ }^{3} \mathrm{H}$-thymidine incorporation (E) and cell counts (F), indicating no effects of BDNF on cellular proliferation.

triplicate and the statistical data are presented in (Fig. 2L). It is noted that due to potent cytotoxicity of camptothecin almost all apoptotic cells were overlapped with necrotic cells. This suggests that cells suffer a sudden death in such a short period of time or such a manner so that both apoptosis and necrosis occur simultaneously.

$B D N F$ increases the expression of $p$-Akt, p-p65, and Bcl2 in OC1 cells. To study whether BDNF protects cells from death via the PI3K/Akt signaling pathway, cells were incubated with and without BDNF in a time-dependent manner. It was found that BDNF increased the expression of activated Akt (p-Akt) from approximately $50 \%$ to $90 \%$ within 5 minutes. The activation of Akt persisted in OC1 cells up to 60 minutes (Fig. 3A). To study whether BDNF-induced pAkt is dependent upon PI3K, cells were incubated with LY294002 for 2 days. It was demonstrated that BDNF induced p-Akt was abrogated in cells treated with LY294002 (Fig. 3B, upper). We then examined the other effectors of BDNF signaling pathway: p-p65 and Bcl-2 using FACS on cells treated with BDNF. It was found that LY294002 abrogated the effect of BDNF on p-p65 and Bcl-2 but increased the expression of caspase 3, an early apoptosis cell marker, by FACS (Fig. 3B, middle upper, lower, and bottom). To study whether BDNF increases cellular survival of OC1 cells by cross-activation of the Erk signaling pathway, cells were incubated with PD98059 for 4 days, a specific inhibitor for Erk, and harvested for evaluation of viable cells using Trypan blue exclusion. It was found that blockage of both PI3K by LY294002 and Erk by PD98059 significantly reduced viable cell numbers in both BDNF-treated and untreated cells compared with controls (Fig. 3C). To study whether $\mathrm{PI} 3 \mathrm{~K}$ mediates phosphorylation of Akt in OC1, cells were plated to chamber slides for 16-20 hours, starved for 24 hours (inactivation of $\mathrm{Akt}$ ), and treated with BDNF, and BDNF+LY294002 for 24 hours, and harvested for evaluation of p-Akt expression. It was found that LY294002 inhibited the p-Akt expression induced by BDNF compared with its control (Fig. 3D), suggesting that PI3K triggers the phosphorylation of Akt. 

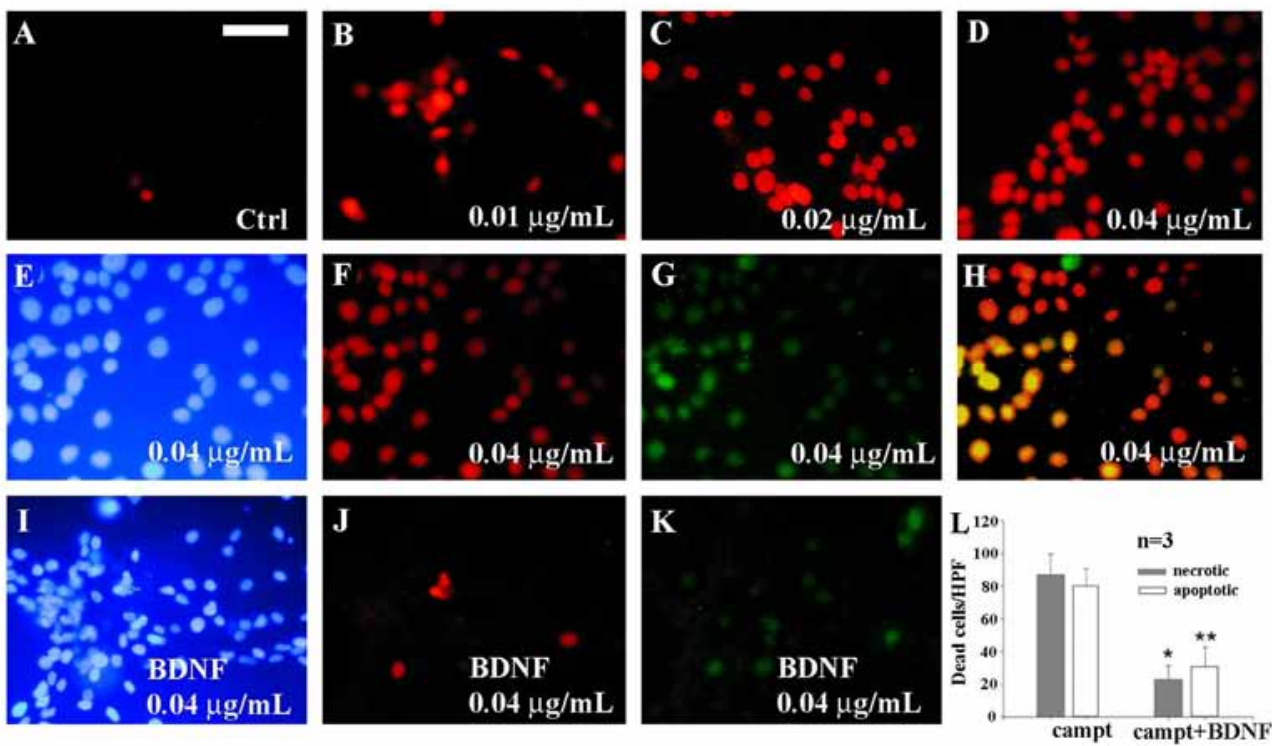

Fig. (2). BDNF reduces OC1 cell death induced by camptothecin. Incubation of OC1 cells with camptothecin from 0 to $0.04 \mu \mathrm{g} / \mathrm{mL}$ caused cell death in a dose-dependent manner (A-D). Camptothecin at $0.04 \mu \mathrm{g} / \mathrm{mL}$ induced the both necrosis (F, red) and apoptosis $(\mathbf{G}$, green) almost in the all cells $(\mathbf{H})$ when compared with DAPI-stained nuclei $(\mathbf{E}$, blue). BDNF at a concentration of $20 \mathrm{ng} / \mathrm{mL}$ reduced camptothecin-induced cell death (I-K). There were fewer cells undergoing necrosis $(\mathbf{J})$ and apoptosis $(\mathbf{K})$ compared with their counterparts $(\mathbf{F}-\mathbf{G})$. Color in red indicating necrotic cells; color in green indicating apoptotic cells; color in yellow indicating both apoptotic and necrotic cells. Panels $\mathbf{E}-\mathbf{H}$ were from the same HPF and panels I-K were also from the same HPF. Bar=50 $\mu$ applying to A-K. Cell counts undergoing cellular death (necrotic and apoptotic) by camptothecin in the presence and absence of BDNF are summarized in $(\mathbf{L})$ that represents experiments in triplicate $(\mathrm{n}=3$, each from 6 HPFs). ${ }^{*} \mathrm{p}<0.05, * * \mathrm{P}<0.05$.

Inhibition of $N F-\kappa B$ with specific inhibitors (PDTC) and I $\mathrm{K} \alpha \mathrm{M}$ abrogates $B D N F$-induced cell survival. As shown above, BDNF increased the expression of phosphorylated NF-кB subunit p65 (p-p65). We examined whether BDNF increases OC1 survival via NF-kB. Cells in chamber slides or T25 flasks were incubated with and without BDNF for 3 days in the presence and absence of PDTC and cells were then harvested for evaluation of apoptotic cells by Yopro-1 and caspase 3 by FACS. The results demonstrated that the BDNF-induced cellular survival was abrogated by PDTC, as judged by Yopro-1 stain (Fig. 4A-F) or caspase 3 expression (Fig. 4H). Percentage of apoptotic cells was significantly higher in BDNF+PDTC treated cells than in BDNF treated cells (Fig. 4G). To verify that BDNF protects cell survival of

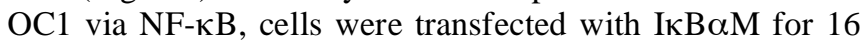
hours in transfection media, recovered in FGM for 24 hours, incubated with BDNF at $10 \mathrm{ng} / \mathrm{mL}$ for 24 hours, and then harvested for evaluation of apoptosis by FACS (7-AAD and annexin V). It was found that IкB $\alpha \mathrm{M}$ increased the percentage of 7-AAD and annexin $\mathrm{V}$ positive cells (Fig. 5).

$B D N F$ and its effectors, $p-A k t, N F-\kappa B$, and Bcl-2 are expressed in the developing cochlea of rats. The above in vitro studies indicate that the PI3K/Akt and NF- $\mathrm{KB} / \mathrm{Bcl}$ signaling pathways exist in $\mathrm{OC} 1$ cells. It is not clear whether they exist in the cochlear tissue of rats. To this end, Affymetrix microarrays on the rat cochlear tissues were performed. As expected, the expression of BDNF and its signaling molecules including receptor (TrkB), kinases (PI3K and Akt), and effectors (NF-кB, Bcl-2, IAP, BAD, and Bok) in the developing cochlear tissue of rats from E12 to P1 in the entire dissected otocysts or otocapsules was observed (Fig. 6A, right).
Semi-quantitative data for BDNF, TrkB, PI3K, Akt, Bcl-2, and IAP are presented in Fig. 6, (left). Immunhistochemistry verified that $\mathrm{p}$-Akt was positive in the otocyst epithelial cells (both cytosol and nuclei, Fig. 6B) and p65 (NF-кB subunit) was strongly positive in inner hair cells (IHC) but rather weak in outer hair cells (Fig. 6C).

\section{DISCUSSION}

Sensory epithelial cells are thought to depend for survival on unidentified factors from auditory epithelial cells in an autocrine or paracrine manner. In this study, we demonstrated that BDNF was expressed in the developing cochlear tissue. The importance of BDNF for nerve ending innervation is known $[29,30]$ whereas the importance of BDNF in hair cell survival is not. The current study demonstrated that BDNF and its related signaling pathways are active in the developing cochlear tissue, especially in the otocyst stage of rats.

Microarray data suggest that BDNF is slightly downregulated from E12 to P1, possibly due to a rapid expansion of non-neuroepithelial cells such as fibroblasts in the late embryonic stage and early postnatal days. However, TrkB, NF$\kappa \mathrm{B} 1$, and Bcl-2 are slightly upregulated from E12 to P1. This may reflect that the PI3K/Akt signaling pathway is slightly

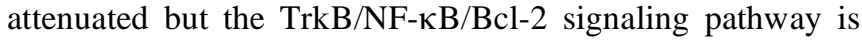
somewhat strengthened. Indeed, immunohistochemistry verifies that p-Akt is highly positive in the otocyst epithelial cells whereas NF-кB subunit p65 is strong in the inner ear hair cells on the postnatal day 14. The expression of NF- $\kappa B$ subunit p65 in the P14 organ of Corti and spiral ganglion suggesting that BDNF and its signaling pathway is not only 
A
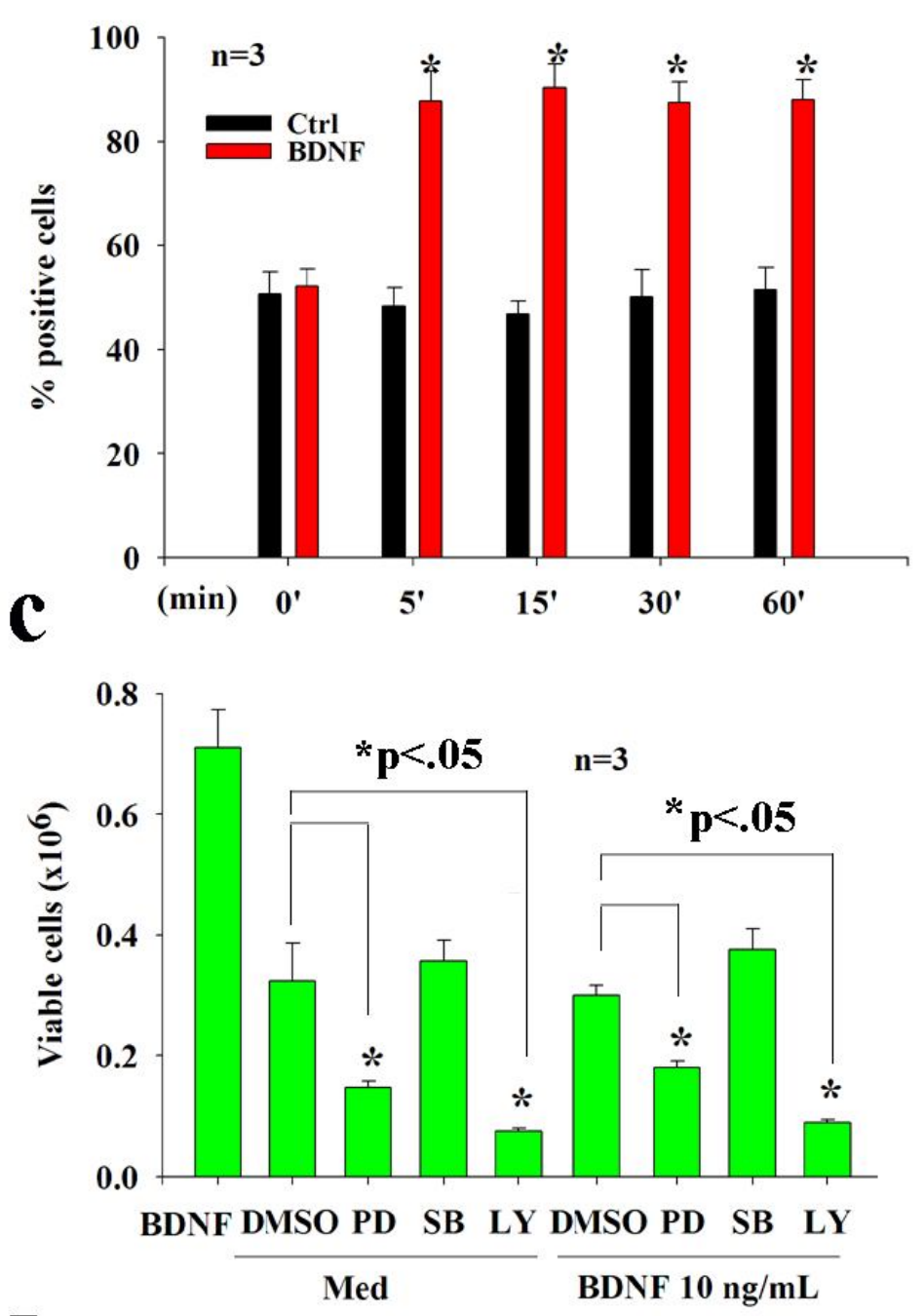

D
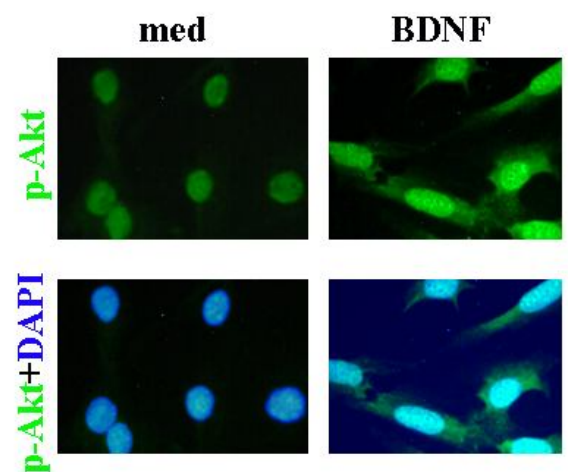

BDNF+LY
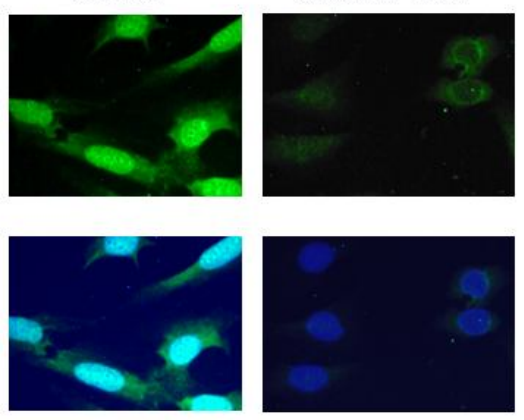

B
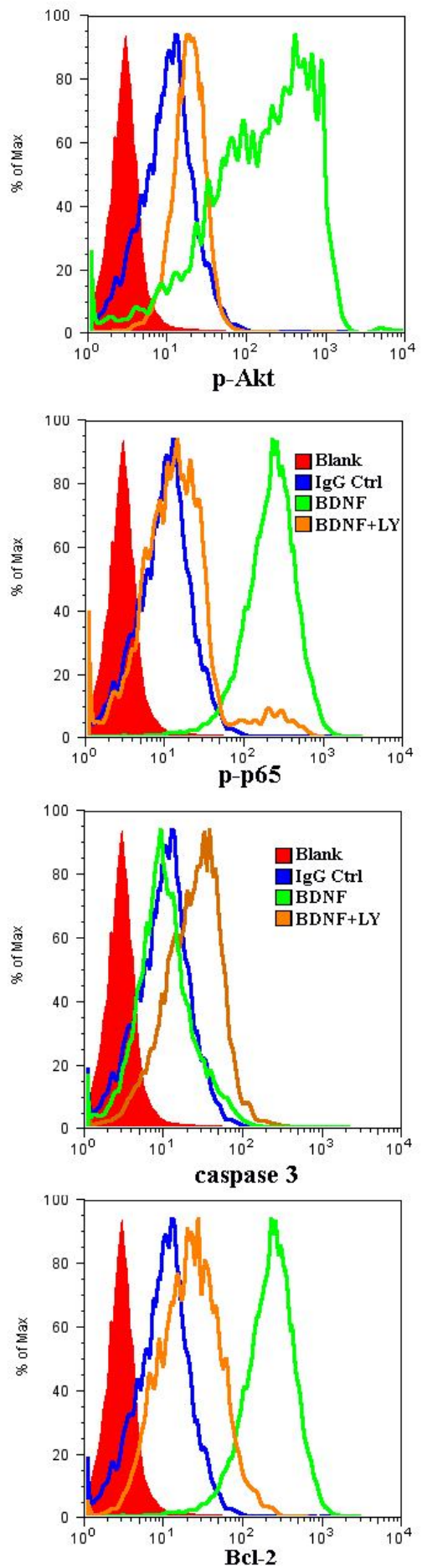

Fig. (3). BDNF protects OC1 cells from death via the PI3K/Akt signaling pathway. In control cells, there was a baseline activity of p-Akt and BDNF significantly increased the phosphorylated Akt (p-Akt) from 5 to 60 minutes by FACS (A). BDNF activated the phosphorylation of Akt and p65 (p-Akt and p-p65) and increased the positive cell percentage of Bcl-2 but BDNF-induced actions on p-Akt, p-p65, and Bcl-2 were abrogated by a specific inhibitor:LY (B). It is noted that the caspase 3 intensity shifted to right in the presence of LY. Trypan blue exclusion demonstrated that bloackage of both PI3K by LY and Ikk by PD significantly reduced viable cells compared with vehicle control (DMSO, p < 0.05) (C). Inhibition of the p38 signaling pathway by SB did not affected the cell viability compared with DMSO. By immunohistochemistry, BDNF increased the level of p-Akt compred with control (med) whereas LY inhibited the BDNF-induced p-Akt compared with BDNF (D). Ctrl IgG, non-specific IgG; PD, PD98059; SB, SB225002; LY, LY294002; med, medium. 

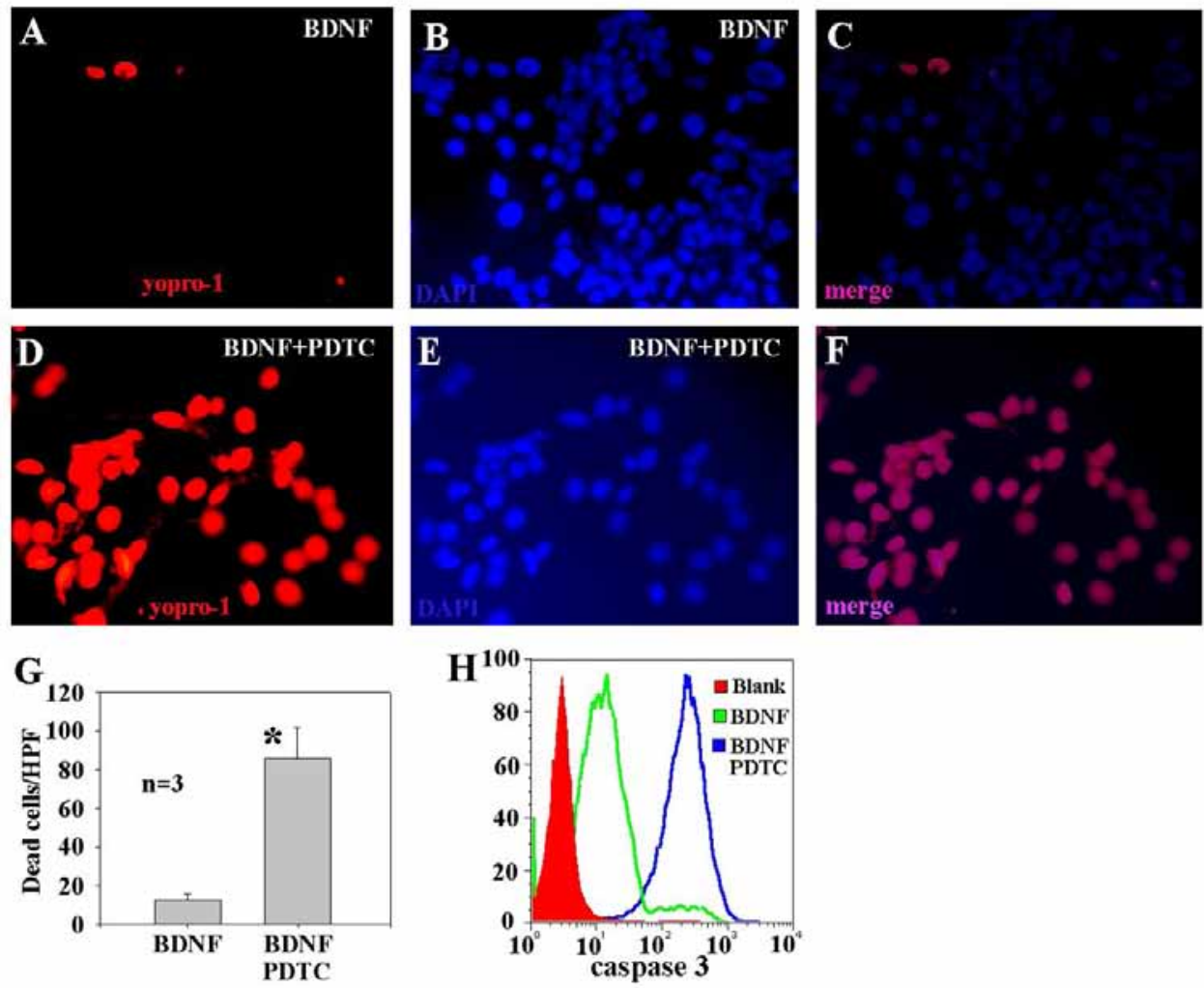

Fig. (4). NF-kB inhibitor (PDTC) abrogates the cellular survival by BDNF. No or few cells stained with Yopro-1 probe when OC1 cells were incubated with BDNF (A-C). Many cells underwent necrosis when NF-кB was inhibited by PDTC (D-F). Dead cells in BDNF+PDTC group were significantly higher than those in BDNF group $(\mathbf{G})$. Caspase 3, an indicator of cellular apoptosis, was significantly higher in BDNF+PDTC treated cells than in BDNF treated cells $(\mathbf{H}) .{ }^{*} \mathrm{p}<0.05$.

active in the developing otocyst epithelium but also active in the P14 organ of Corti, especially in the inner hair cells. Apparently, NF- $\mathrm{KB}$ subunit $\mathrm{p} 65$ is highly expressed in the inner hair cells and spiral ganglion but not in the outer hair cells and non-sensorineural components. It suggests that inner hair cells and spiral ganglion are well protected by the BDNF signaling pathways whereas outer hair cells are not. This may in part explain why outer hair cells are readily damaged by noise, aminoglycosides, and other toxic agents whereas inner hair cells are not.

Our in vitro data demonstrated that BDNF plays a role in the survival of sensory epithelial cells. BDNF increases viable cells and reduces apoptotic cells but it does not significantly increase thymidine incorporation, and cell number increase within a short period of time (12 hours). BrdU incorporation also shows a non-significant increase of cell proliferation. However, BDNF shows an increased tendency of viable cells for a longer time (72 hours) because apoptotic cells are reduced. These data suggests that BDNF in the cochlear tissue may play a role in the protection of cells from death, instead of cell growth and proliferation. This is consistent with the literature data in which knockout of Brn3.1, a gene controlling the production of BDNF, makes sensory hair cells short-lived in animals [4-6,7].

The question we raised here is whether BDNF plays a role in the survival of sensory epithelial cells. If so, it should be able to protect $\mathrm{OC} 1$ cells from death induced by cytotoxic agents such as camptothesin, a universal inducer of cellular apoptosis. As shown in this study, BDNF protects sensory epithelial cells from death by camptothecin which is a potent inducer of OC1 apoptosis. Consistent with our observation, BDNF protects aminoglycoside antibiotic-induced cellular apopotosis in animals [31] as indicated in the literature. The accumulating and emerging evidence suggests that BDNF may play a critical role in the protection of sensory hair cells from death and may be useful for prevention of hair cell degeneration against extensive ototoxic lesions in the organ of Corti.

How does BDNF increase the survival of sensory epithelial cells? First, BDNF binds to its receptor TrkB. TrkB contains the activity of tyrosine kinase which, in turn, activates the PI3K. PI3K phosphorylates phosphatidylinositols of the cell membrane and thus generates phosphatidylinositol3,4,5-phosphate (PIP3) from phosphatidylinositol-4,5phosphate (PIP2) which then recruits protein kinases such as Akt to the plasma membrane and subsequent cascade ensues which is relevant for a variety of cellular responses. Activated Akt then cross-talks to the mitogen-activated protein kinase (Erk) that leads to the activation and translocation of

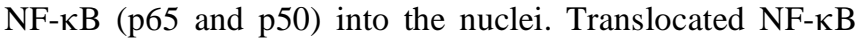
then binds to the Bcl-2 promoter [14] and regulates the expression of $\mathrm{Bcl}-2$ which inactivates the caspase 3 , an enzyme for initiation of cellular apoptosis. This may be the signaling pathway for BDNF to protect OC1 cells from apoptosis. 

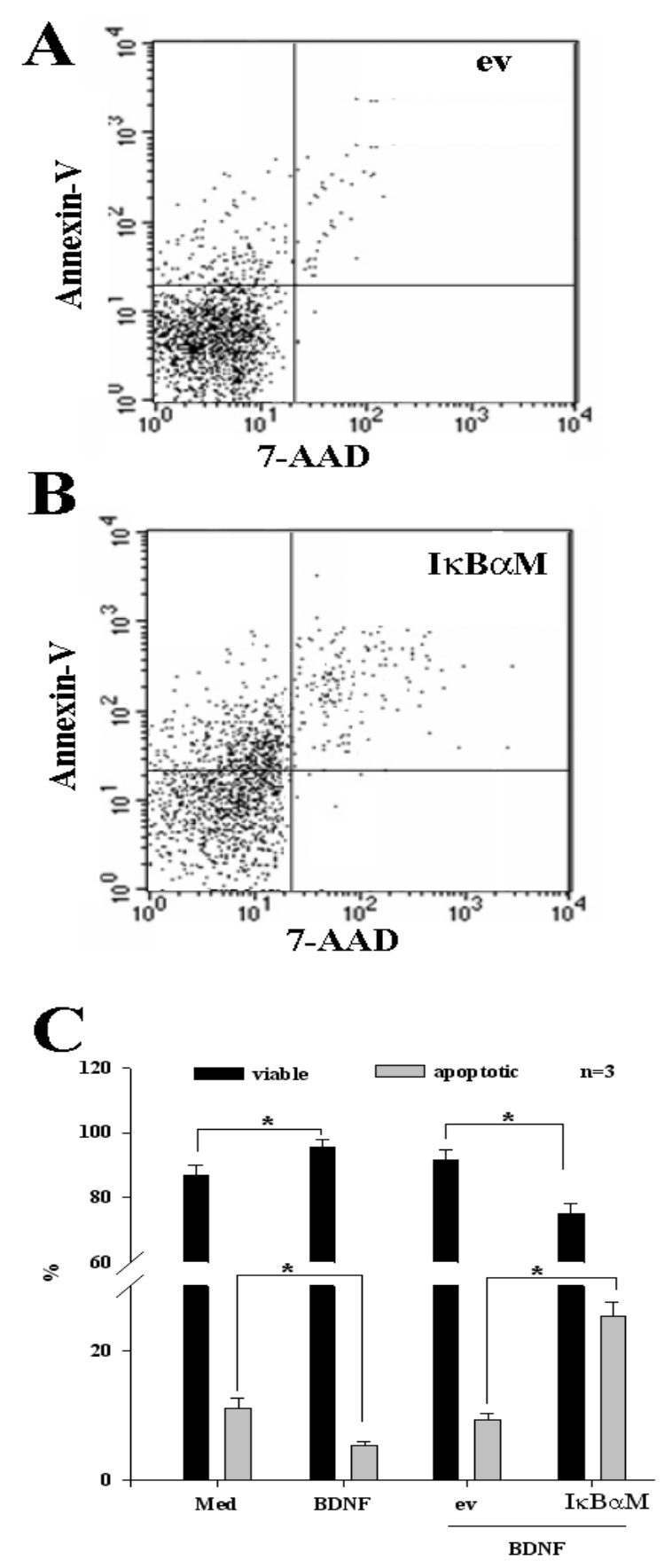

Fig. (5). I $\kappa \mathrm{B} \alpha \mathrm{M}$, a specific inhibitor of NF- $\kappa \mathrm{B}$ activity, abrogates the cellular survival of OC1 by BDNF. Cells were transfected with IкB $\alpha \mathrm{M}$ and empty vector (ev), challenged with BDNF, and harvested for evaluation of apoptotic cells by double staining FACS (7-AAD and Annexin-V, 7-AAD for late apoptosis and Annexin-V for early apoptosis). A representative dot plot for 7-AAD positive and/or Annexin- $\mathrm{V}$ positive cells after transfection with ev is presented in (A) and a representative dot plot for 7-AAD positive and Annexin-V positive cells after transfection with IкB $\alpha M$ is shown in (B). Percentage of apoptotic cells was significantly higher in IкB $\alpha \mathrm{M}$ transfectants than in empty vector transfectants but percentage of viable cells was significantly lower in IкB $\alpha \mathrm{M}$ transfectants than in empty vector transfectants $\left(\mathbf{C},{ }^{*} \mathrm{p}<0.05, \mathrm{n}=3\right)$. Med, medium.
A

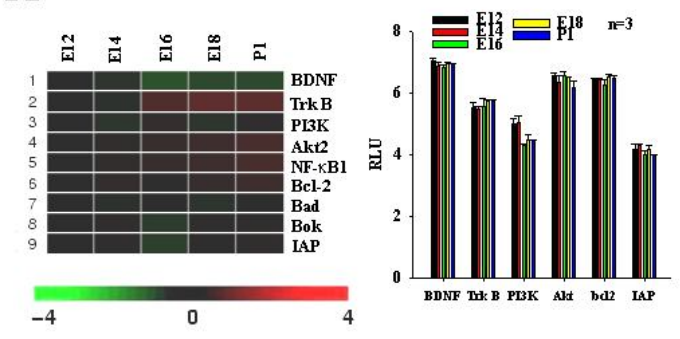

B

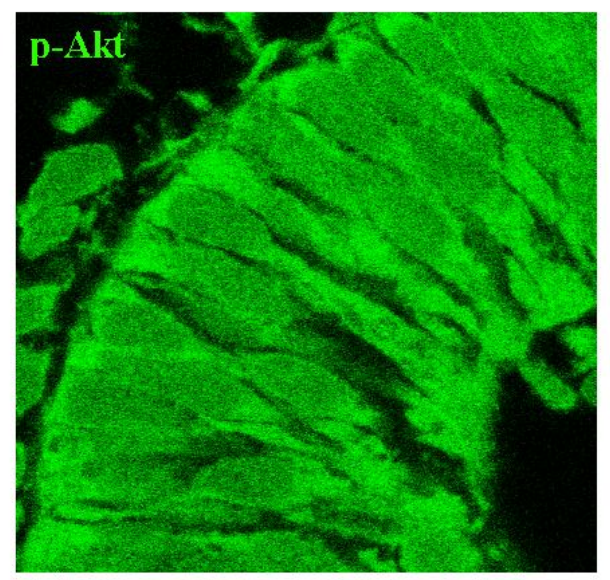

C

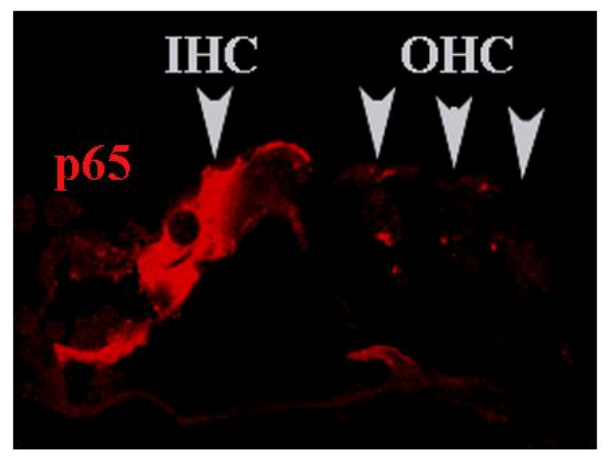

Fig. (6). Expression of BDNF and its signaling molecule profile in the developing cochlear tissue of rats. Expression of the BDNF, Trk $\mathrm{B}, \mathrm{Akt}, \mathrm{NF}-\mathrm{\kappa B}, \mathrm{Bcl}-2$, inhibitor of apoptosis protein (IAP), and proapoptotic proteins (Bok and Bad) from E12 to P1 at the mRNA level by Affymetrix microarrays (A, right panel, heatmaps for the averaged expression of 3 independent batches of mRNA samples). It is noted that the mRNAs transcripts from E12 to P1 demonstrated that BDNF and PI3K slightly reduced but Trk B, NF-кB, and Bcl-2 increased as judged by color changes and semiquantitative measurement of the same data verifies this adjustment along the devel-

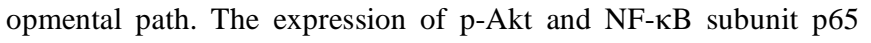
was verified by immunohistochemistry (B-C). It is noted that $\mathrm{p}-\mathrm{Akt}$ was extensively expressed in the entire otocyst epithelial layer at E12 (B) but p65 was remarkably positive in the inner hair cell (IHC) but not in the out hair cells at P14 (C).

A key step in the above cascade is activation of PI3K. As such, blockage of PI3K should inhibit the effects of BDNF on cellular survival. Indeed, our in vitro studies clearly indicate that blockage of PI3K with LY294002 abrogates the 
protective effect of BDNF on sensory epithelial cells. Inhibition of PI3K with LY294002 cancels out the effect of BDNF on the activity of NF-KB and expression of Bcl-2. In addition, inhibition of NF- $\mathrm{KB}$ by PTDC increases the expression of caspase 3. It suggests that the both Akt and NF-KB pathways are equally important in keeping sensory epithelial cells viable. Whether these pathways are of importance in protection of sensory epithelial cells from death by noise, ototoxicity drugs, and other lesions needs further studies.

\section{CONFLICT OF INTEREST}

The author(s) confirm that this article content has no conflicts of interest.

\section{ACKNOWLEDGEMENT}

This study is in part supported by the Fujian International Collaboration project of Science and Technical Reserch; Contract grant number: 2008I0017, Youth Foundation of Fujian Provincial Health Department (grant number :2012-121, and the Lions 5M International Hearing Foundation. We would like to thank Ms. Ellalane Bearth for her editorial assistance in the preparation of this manuscript.

\section{REFERENCES}

[1] Lu J, Wu Y, Sousa N, Almeida OF. SMAD pathway mediation of BDNF and TGF beta 2 regulation of proliferation and differentiation of hippocampal granule neurons. Development 2005; 132: 3231-42.

[2] Fritzsch B, Silos-Santiago I, Bianchi LM, Farinas I. The role of neurotrophic factors in regulating the development of inner ear innervation. Trends Neurosci 1997; 20: 159-64.

[3] Pirvola U, Ylikoski J, Palgi J, Lehtonen E, Arumae U, Saarma M. Brain-derived neurotrophic factor and neurotrophin 3 mRNAs in the peripheral target fields of developing inner ear ganglia. Proc Natl Acad Sci USA 1992; 89: 9915-9.

[4] Clough RL, Sud R, Davis-Silberman N, et al. Brn-3c (POU4F3) regulates BDNF and NT-3 promoter activity. Biochem Biophys Res Commun 2004; 324: 372-81.

[5] Sud R, Jones CM, Banfi S, Dawson SJ. Transcriptional regulation by Barhl1 and Brn-3c in organ-of-Corti-derived cell lines. Brain Res Mol Brain Res 2005; 141: 174-80.

[6] Smith MD, Morris PJ, Latchman DS. The Brn-3c transcription factor contains a neuronal-specific activation domain. Neuroreport 1998; 9: 851-6.

[7] Xiang M, Gao WQ, Hasson T, Shin JJ. Requirement for Brn-3c in maturation and survival, but not in fate determination of inner ear hair cells. Development 1998; 125: 3935-46.

[8] Vahava O, Morell R, Lynch ED, et al. Mutation in transcription factor POU4F3 associated with inherited progressive hearing loss in humans. Science 1998; 279: 1950-4.

[9] Chung WH, Pak K, Lin B, Webster N, Ryan AF. A PI3K pathway mediates hair cell survival and opposes gentamicin toxicity in neonatal rat organ of Corti. J Assoc Res Otolaryngol 2006; 7: 373-82.

[10] Dudek H, Datta SR, Franke TF, et al. Regulation of neuronal survival by the serine-threonine protein kinase Akt. Science 1997; 275: 661-5.

[11] Hemmings BA. Akt signaling: linking membrane events to life and death decisions. Science 1997; 275: 628-30.
[12] Gingery A, Bradley E, Shaw A, Oursler MJ. Phosphatidylinositol 3-kinase coordinately activates the MEK/ERK and AKT/NFkappaB pathways to maintain osteoclast survival. J Cell Biochem 2003; 89: 165-79.

[13] Jiang H, Sha SH, Schacht J. NF-kappaB pathway protects cochlear hair cells from aminoglycoside-induced ototoxicity. J Neurosci Res 2005; 79: 644-51.

[14] Dixon EP, Stephenson DT, Clemens JA, Little SP. Bcl-Xshort is elevated following severe global ischemia in rat brains. Brain Res 1997; 776: 222-9.

[15] Ozeki M, Hamajima Y, Feng L, et al. Id1 induces the proliferation of cochlear sensorineural epithelial cells via the NF-kB/cyclin D1 pathway in vitro. J Neurosci Res 2007; 85: 515-24.

[16] Ozeki M, Duan L, Obritch W, Lin J. Establishment and characterization of progenitor hair cell lines in rats. Hear Res 2003; 179: 4352.

[17] Lin J, Ozeki M, Javel E, et al. Identification of gene expression profiles in rat ears with cDNA microarrays. Hear Res 2003; 175: 213.

[18] Ozeki M, Schlentz EP, Lin J. Characterization of inhibitor of differentiation (Id3) gene expression in the developing cochlear tissue of rats. Acta Otolaryngol 2005; 125: 244-9.

[19] Lendahl U, Zimmerman LB, McKay RD. CNS stem cells express a new class of intermediate filament protein. Cell 1990; 60: 585-95.

[20] Frederiksen K, McKay RD. Proliferation and differentiation of rat neuroepithelial precursor cells in vivo. J Neurosci 1988; 8: 114451.

[21] Nurmi A, Vartiainen N, Pihlaja R, Goldsteins G, Yrjanheikki J, Koistinaho J. Pyrrolidine dithiocarbamate inhibits translocation of nuclear factor kappa-B in neurons and protects against brain ischaemia with a wide therapeutic time window. J Neurochem 2004; 91: 755-65.

[22] Van Antwerp DJ, Martin SJ, Kafri T, Green DR, Verma IM. Suppression of TNF-alpha-induced apoptosis by NF-kappaB. Science 1996; 274: 787-9.

[23] Gilmore TD, Koedood M, Piffat KA, White DW. Rel/NFkappaB/IkappaB proteins and cancer. Oncogene 1996; 13: 136778.

[24] Fujita T, Nolan GP, Liou HC, Scott ML, Baltimore D. The candidate proto-oncogene bcl-3 encodes a transcriptional coactivator that activates NF-kappa B p50 homodimers. Genes Dev 1993; 7: 135463 .

[25] Adams JP, Roberson ED, English JD, Selcher JC, Sweatt JD MAPK regulation of gene expression in the central nervous system. Acta Neurobiol Exp (Wars) 2000; 60: 377-94.

[26] Lin J, Feng L, Fukudome S, Hamajima Y, Huang T, Levine S Cochlear stem cells/progenitors and degenerative hearing disorders. Curr Med Chem 2007; 14: 2937-43.

[27] Lee Y-W, Ozeki M, Juhn SK, Lin J. Expression of platelet-derived growth factor in the developing cochlea of rats. Acta Otolaryngol 2004; 124: 558-62.

[28] Krysan K, Dalwadi H, Sharma S, Pold M, Dubinett S. Cyclooxygenase 2-dependent expression of survivin is critical for apoptosis resistance in non-small cell lung cancer. Cancer Res 2004; 64: 6359-62.

[29] Alderson RF, Alterman AL, Barde YA, Lindsay RM. Brain-derived neurotrophic factor increases survival and differentiated functions of rat septal cholinergic neurons in culture. Neuron 1990; 5: 297306.

[30] Ventimiglia R, Mather PE, Jones BE, Lindsay RM. The neurotrophins BDNF, NT-3 and NT-4/5 promote survival and morphological and biochemical differentiation of striatal neurons in vitro. Eur J Neurosci 1995; 7: 213-22.

[31] Lopez I, Honrubia V, Lee SC, et al. The protective effect of brainderived neurotrophic factor after gentamicin ototoxicity. Am J Otol 1999; 20: 317-24.

(C) Huang et al.; Licensee Bentham Open.

This is an open access article licensed under the terms of the Creative Commons Attribution Non-Commercial License (http://creativecommons.org/licenses/by-nc/3.0/) which permits unrestricted, non-commercial use, distribution and reproduction in any medium, provided the work is properly cited. 